\title{
Effect of Sertraline on Glucocorticoid Sensitivity of Mononuclear Leukocytes in Post-Traumatic Stress Disorder
}

\author{
Rachel Yehuda*,', Ren-Kui Yang', Julia A Golier', Robert A Grossman', Linda M Bierer' and Lisa Tischler' \\ 'The Traumatic Stress Studies Program, Department of Psychiatry, Mount Sinai School of Medicine and the Bronx Veterans Affairs Medical \\ Center, Bronx, NY, USA
}

\begin{abstract}
This study examined the effects of sertraline (SER) on glucocorticoid sensitivity in mononuclear leukocytes (MNL) from eight subjects with current post-traumatic stress disorder (PTSD) and nine comparison subjects. In all, $60 \mathrm{ml}$ of blood was withdrawn by venipuncture at 0800 , and $M N L$ were isolated from blood and divided into two portions: the first contained live cells incubated with a series of concentrations of dexamethasone (DEX); the second contained cells incubated with similar concentrations of DEX $+2 \mu M$ SER. Group difference in the concentrations of DEX required to inhibit lysozyme activity by $50 \%$ were evaluated under conditions of DEX-only and DEX + SER using analysis of covariance (ANCOVA). A significant Group $\times$ Condition interaction reflected that SER altered the lysozyme $I_{50-D E X}$ in the direction of decreasing sensitivity to glucocorticoids in PTSD while having no uniform effect in cells from comparison subjects. The data provide support for the idea that glucocorticoid receptors might be more responsive to antidepressants in PTSD than in persons without PTSD. Insofar as increased sensitivity to glucocorticoids has been linked with PTSD, the actions of SER on the lysozyme $I_{50-D E X}$ suggest that this medication may target a biologic alteration associated with PTSD pathophysiology.

Neuropsychopharmacology (2006) 3 I, I89-196. doi: I0.1038/sj.npp. I 300862; published online I0 August 2005
\end{abstract}

Keywords: sertraline; SSRI; antidepressants; glucocorticoid receptors; lysozyme activity; post-traumatic stress disorder; mononuclear leukocytes

\section{INTRODUCTION}

An early rationale for investigating the efficacy of antidepressants in the treatment of post-traumatic stress disorder (PTSD) was the symptom overlap and comorbidity between PTSD and major depressive disorder (MDD) (Yehuda et al, 2002). The selective serotonin reuptake inhibitor (SSRI), sertraline (SER), is currently one of two medications approved by the Food and Drug Administration for the treatment of both PTSD and MDD, and is a first line pharmacologic treatment for both disorders (Brady et al, 2000; Davidson et al, 2001; Nemeroff and Owens, 2004).

Numerous investigations of the mechanisms of action of antidepressants in depressed patients, as well as animal and cellular models, have examined the effects of these medications on biologic alterations considered to be central to the pathophysiology of depression. Initial work in this area revealed striking effects of antidepressants in enhan-

\footnotetext{
*Correspondence: Dr R Yehuda, Psychiatry II6A, Bronx Veterans Affairs, 130 West Kingsbridge Road, Bronx, NY 10468, USA, Tel: + I 7I8 5849000 ext. 6964, Fax: + I 7I8 74| 4775,

E-mail: Rachel.Yehuda@med.va.gov

Received 12 January 2005; revised I 8 May 2005; accepted 6 June 2005 Online publication: 7 July 2005 at http://www.acnp.org/citations/ Npp070705050029/default.pdf
}

cing GR-mediated gene transcription (Pepin et al, 1989, 1992). Further work has clarified that most antidepressants, including SSRI's, enhance cortisol action in the brain and periphery by inhibiting membrane steroid transporters that regulate the intracellular concentration of cortisol, principally by expelling cortisol from the cell (Pariante et al, 1997, 2001, 2003a,b; Weiss et al, 2003). Although membrane steroid transporter inhibition has been shown to occur independently of glucocorticoid-receptor mediation, and instead, is affected directly by the physiochemical properties of antidepressants (Ford, 1996; Castaing et al, 2000; Ekins et al, 2002), this action could result in an augmentation of negative feedback inhibition of the HPA axis - an effect consistent with the reversal of at least one known perturbation in MDD - reduced negative feedback inhibition (Nemeroff, 1996; Holsboer, 2000; Pariante and Miller 2001; McQuade and Young, 2000).

In PTSD, evidence has emerged for an enhanced cortisolnegative feedback inhibition (Yehuda et al, 1995, 1996) possibly reflecting increased glucocorticoid receptor (GR) sensitivity (Yehuda, 2002; Yehuda et al, 2004). These alterations are clearly opposite to those seen in about half of patients with MDD, raising questions about the effects of SSRIs on HPA axis parameters in PTSD.

The purpose of this study was to examine the in vitro effects of SER in a model of functional glucocorticoid 
sensitivity in mononuclear leukocytes (MNL) from subjects with PTSD and healthy, nonpsychiatric controls. The human peripheral blood mononuclear cell provides an excellent environment for the study of the direct effects of SSRI's on glucocorticoid sensitivity because this cell does not contain noradrenaline or serotonin reuptake sites (Okugawa et al, 1999; Hery et al, 2000; Lai et al, 2003). Thus, effects of SER that would be observed on glucocorticoid-related measures are of necessity unrelated to the inhibition of noradrenaline or serotonin reuptake, mechanism(s) considered to be central in the therapeutic action of SSRIs (Nestler, 1998; Schafer, 1999).

We have recently demonstrated that lower concentrations of dexamethasone (DEX) were required to inhibit lysozyme synthesis in MNL from subjects with PTSD than comparison subjects, reflecting a greater sensitivity to glucocorticoids (Yehuda et al, 2004). The lysozyme $\mathrm{IC}_{50-\mathrm{DEx}}$ generated by this in vitro dose-response study was found to be significantly associated with the plasma cortisol response to oral DEX ingestion (Yehuda et al, 2003), a well-known measure of glucocorticoid-negative feedback inhibition (Cole et al, 1999). In the current study, we examined the effects of SER administration on DEX-inhibited lysozyme activity in MNL from eight subjects with PTSD and nine comparison subjects. In view of the fact that enhanced glucocorticoid sensitivity in PTSD may be relevant to the pathophysiology of PTSD, we hypothesized that the effect of SER would be to increase the lysozyme $\mathrm{IC}_{50-\mathrm{DEX}}$, reflecting decreased cellular sensitivity to glucocorticoids.

\section{PATIENTS AND METHODS}

\section{Subjects}

In all, 17 subjects were studied. Recruitment was through advertisements placed in local newspapers or on bulletin boards around the Mount Sinai Hospital and the Bronx Veteran Affairs Medical Center (VAMC) requesting volunteers for research examining hormonal responses following extremely stressful life events. The Institutional Review Boards at the Mount Sinai School of Medicine and the Bronx Veterans Affairs approved all procedures, and all subjects provided written informed consent prior to participation. Healthy controls were free from current or lifetime Axis I disorder, except that subjects with past substance abuse, were included if they were in sustained full remission. Subjects in the PTSD group were excluded if they had an Axis I disorder other than PTSD, unless this disorder was a comorbid anxiety or depressive disorder. Also excluded were participants with major medical, endocrinological, or neurological disorders likely to interfere with HPA axis function. Subjects were not withdrawn from medications to participate in the study. However, because we wished to eliminate confounds associated with the effects of other medications, we excluded subjects who were taking any type of medication for psychiatric illness.

\section{Clinical Assessments}

Information about traumatic life events was obtained using the Trauma History Questionnaire (THQ) (Green, 1996), and was reviewed with the subject in order to ascertain whether they met the diagnostic criteria, 'Criterion A,' for a traumatic event (ie involved actual or perceived threat of serious harm, and provoked a response of intense fear, helplessness or horror) (American Psychiatric Association, 1994). Subjects also completed the Childhood Trauma Questionnaire (Bernstein et al, 1994), which asks about experiences of emotional and physical abuse and neglect and sexual abuse. Subjects who endorsed a Criterion A event were evaluated with the Clinician Administered PTSD Scale (CAPS) (Blake et al, 1995), using the most disturbing experience as the basis of the CAPS interview. Other Axis I diagnoses were made using the Structured Clinical Interview for DSM-IV (Spitzer et al, 1995). A trained psychologist or psychiatrist with established inter-rater reliability, conducted diagnostic interviews, and diagnoses were confirmed by consensus conference.

Estimates of severity of symptoms were made on the basis of self-administered PTSD and depression instruments. These instruments included the Post Traumatic Stress Disorder Checklist (PCL) (Blanchard et al, 1996) and the Beck Depression Index (BDI) (Beck et al, 1961), and were completed by the subject immediately following blood withdrawal.

\section{Laboratory Methods}

Plasma and lymphocytes preparation. In all, $60 \mathrm{ml}$ blood was drawn in tubes containing EDTA. Cells were separated from platelet-rich plasma by centrifugation at $300 \mathrm{~g}$ for $15 \mathrm{~min}$ at room temperature. After adding the same volume of Hanks-balanced salt solution (HBS) as plasma had been aspirated, the lymphocytes were isolated by Ficoll-Paque gradient method (Ficoll-Paque PLUS, Amershan Pharmacia Biotech, Piscataway, NJ) using ACCUSPIN Tubes (Sigma, St Louis, MO). After washing two times in ice-cold HBS, 6-8 $\mathrm{ml}$ cold HBS was added into the pellet tube. In all, $100 \mu \mathrm{l}$ of the suspension was counted by a hemocytometer. The $1-2 \mathrm{ml}$ suspension, usually containing $0.5-2 \times 10^{7}$ cells, was pelleted by centrifuge and stored at $-70^{\circ} \mathrm{C}$ for GR-binding assay. The rest of cell suspension was repelleted and resuspended in cold RPMI-1640 medium supplemented with $10 \%(\mathrm{~V} / \mathrm{V})$ fetal bovine sera, $50 \mathrm{U} / \mathrm{ml}$ penicillin and $50 \mu \mathrm{g} / \mathrm{ml}$ streptomycin (Gibco, Life Technologies Ltd, Grand Island, NY). The concentration of cell was 3.5$4.0 \times 10^{5}$ cells $/ 150 \mu \mathrm{l}$ using for lysozyme inhibition test. The platelet-rich plasma was centrifuged at $2700 \mathrm{~g}$ for $15 \mathrm{~min}$ at $4^{\circ} \mathrm{C}$. The platelet-poor plasma was collected for cortisol assay.

GR-binding assay. Receptor binding was measured in the cytosolic cell fraction of MNL with the ligand ${ }^{3} \mathrm{H}$-DEX $\left({ }^{3} \mathrm{H}\right.$-DEX, Amershan Pharmacia Biotech, Piscataway, NJ) according to our published method (Yehuda et al, 1995). The interassay and intra-assay coefficients of variation were 5.0 and $8.5 \%$, respectively.

Plasma cortisol assay. Plasma cortisol was determined by radioimmunoassay (RIA) using the 'GammaCoat Cortisol ${ }^{125}$ I RIA Kit' (DiaSorin, Stillwater, MN). The interassay and intra-assay coefficients of variation were 3.0 and $7.7 \%$, respectively. 
Inhibition of lysozyme synthesis by DEX and the effect of $S E R$. We modified the method for assessment of inhibition of lysozyme synthesis by DEX described by Panarelli et al (1994). In brief, $20 \mu \mathrm{l}$ of different concentrations of DEX in HBS were added into 96 flat-bottom wells of a microplate to give a final concentration of $0.5-100 \mathrm{nM}$. HBS $(20 \mu \mathrm{l})$ were added to a control well. Supplemented RPMI-1640 $(50 \mu \mathrm{l})$ in the absence or presence of SER (Pfizer, Inc.) were added to give a final concentration of SER $(2 \mu \mathrm{M})$. In all, $150 \mu \mathrm{l}$ of cell suspension as prepared above were placed into each well. Each sample was run in triplicate. After mixing for $1 \mathrm{~min}$ the plate was incubated for $72 \mathrm{~h}$ in $5 \% \mathrm{CO}_{2} /$ air at $37^{\circ} \mathrm{C}$ in a humidified chamber. After centrifuging the plate, a $120 \mu \mathrm{l}$ aliquot of supernatant was removed and pooled from each of the triplicate wells. The combined supernatant was stored at $-70^{\circ} \mathrm{C}$ until lysozyme assay. We have previously found using this preparation that the lysozyme $\mathrm{IC}_{50 \text {-DEx }}$ correlates with the cortisol response to DEX in healthy (ie without medical or psychiatric disorder) volunteers (Yehuda et al, 2003).

Lysozyme activity in supernatant was measured by a turbidimetric method. Micrococcus lysodeikticus (Sigma, St Louis, MO) was used as substrate, which was prepared in $0.1 \mathrm{M}$ phosphate buffer $\mathrm{pH}$ 6.3. In all, $20 \mu \mathrm{l}$ of supernatant was mixed with $150 \mu \mathrm{l}$ of M. lysodeikticus in a microplate. Assays at each of eight DEX dilutions were performed in triplicate. Each plate (containing an individual dilution in triplicate) was preincubated for 7-10 min and then kinetically read for optical density (OD) at $450 \mathrm{~nm}$ using a VERSA max microplate reader (Molecular Devices, Sunnyvale, CA) at $37^{\circ} \mathrm{C}$ for $20 \mathrm{~min}$. For each dilution of DEX, supernatant was pooled for the assessments of inter- and intra-assay coefficients of variation for measurement of lysozyme activity. These were 4.5 and $9.2 \%$, respectively.

Calculation of lysozyme activity. Relative percent of lysozyme activity (RAL \%) was used for creating a DEX dose-inhibition curve based on the underlying assumption that the activity of lysozyme was $100 \%$ and 0 at DEX $(0 \mathrm{nM})$ and $(100 \mathrm{nM})$, respectively. The calculation for RAL \% in the DEX-only condition was as follows:

$$
\begin{aligned}
& \text { RAL } \%(\text { DEX }- \text { only }) \\
& =\frac{\text { OD at each }(\text { DEX })-\text { OD at DEX }(100 \mathrm{nM})}{\text { OD at DEX }(0 \mathrm{nM})-\text { OD at DEX }(100 \mathrm{nM})} \times 100
\end{aligned}
$$

The OD of the lysozyme preparations were altered by approximately \pm 5 to $10 \%$ by the addition of SER in the absence of DEX, interpreted as a reflection of physiochemical properties of the drug. For each subject, results at each concentration of DEX were corrected for this difference. The calculation for corrected RAL \% (DEX + SER) is as follows:

$$
\begin{aligned}
& \text { Corrected RAL } \%(\text { DEX }+ \text { SER }) \\
& =\frac{\text { Corrected OD at each }(\mathrm{DEX}+\mathrm{SER})-\mathrm{OD} \text { at DEX }(100 \mathrm{nM})}{\text { OD at DEX }(0 \mathrm{nM})-\mathrm{OD} \text { at DEX }(100 \mathrm{nM})}
\end{aligned}
$$$$
\times 100
$$

The DEX concentration that would give 50\% inhibition of lysozyme activity in the absence, $\mathrm{IC}_{50-\mathrm{DEX}}(\mathrm{nM})$, or presence of SER, IC $\mathrm{IC}_{\text {50-DEX-SER }}(\mathrm{nM})$, was derived from the DEX dose-response curve using GraFit software (Sigma, St Louis, MO).
Statistical analysis. Initial analyses were carried out to identify potential confounds in the data. Age, ethnicity, gender, weight, height, body mass index (BMI), nicotine use, and past substance abuse were tested individually for association with the biological outcome measures $\left(\mathrm{IC}_{50-D E X}\right.$ in the presence and absence of SER, baseline cortisol level and GR binding) separately, and in consideration of group. Based on associations between the $\mathrm{IC}_{50-\mathrm{DEX}}+\mathrm{SER}$ and gender and BMI, respectively, these measures were used as covariates for repeated measures $\left(\mathrm{IC}_{50-\mathrm{DEX}} v s \mathrm{IC}_{50-\mathrm{DEX}}+\mathrm{SER}\right)$ analysis of covariance (ANCOVA). To calculate the impact of SER on basal glucocorticoid responsivity in this model, a variable reflecting percent change in $\mathrm{IC}_{50-\mathrm{DEx}}$ from that determined in the DEX-only condition was created $\left(\mathrm{IC}_{50-\mathrm{DEX}}-\mathrm{IC}_{50-\mathrm{DEX}+\mathrm{SER}} / \mathrm{IC}_{50-\mathrm{DEX}}\right) \times 100$. Correlational analyses were performed using Pearson's $r$.

\section{RESULTS}

Demographic, clinical, and biological characteristics of the sample are reported in Table 1. No group differences were present in any of the major demographic variables such as age, gender distribution, ethnicity, height, weight or BMI, current smoking status, or past substance abuse. Five of eight PTSD subjects met diagnostic criteria for current MDD, and two of the remaining subjects met criteria for past MDD. There were significant group differences in severity of PTSD symptoms assessed by the PCL, as well as of depressive symptoms assessed with the BDI. There were also significant group differences in all the biologic variables measured, except for baseline $\mathrm{GR}$ and $\mathrm{IC}_{50 \text {-DEX-SER }}$.

The biological data are presented in Figures 1 and 2 . Figure 1 shows the inhibition curves of lysozyme activity by DEX and the effect of SER to influence this effect in human peripheral MNL in the two groups. Figure 2 shows the $\mathrm{IC}_{50-\mathrm{DEX}}$ before and after SER for each individual within the two groups; the mean values and confidence intervals are reported in the legend. For the $\mathrm{IC}_{50-\mathrm{DEx}}$ (in the absence of SER) there was a significant main effect of group $(\mathrm{F}(1,15)=6.97, p=0.02)$, which persisted after controlling for gender and BMI $(\mathrm{F}(1,13)=8.36, p=0.01)$. By repeated measures ANCOVA there was a significant main effect of SER $(\mathrm{F}(1,13)=6.71, p=0.022)$, a significant group by SER interaction $(\mathrm{F}(1,13)=6.08, p=0.028)$, and no main effect of group $((\mathrm{F}(1,13)=0.16, p=0.69)$. Both gender $(\mathrm{F}(1,13)=$ $8.85, p=0.01)$ and BMI $(\mathrm{F}(1,13)=5.65, p=0.03)$ were significantly associated with $\mathrm{IC}_{50-\mathrm{DEX}}$ in this analysis. The graph illustrates that the effect of SER is to shift the curve towards decreasing the inhibitory effects of DEX, consistent with the main effect of SER in the repeated-measures which reflects a significantly higher IC $_{50-D E X}$ for cells incubated with than without SER (adjusted mean (SE): $7.785 \mathrm{nM}$ (0.703) vs $5.327 \mathrm{nM}$ (0.305), respectively). The significant group by SER interaction indicated a differential effect of SER between PTSD and control samples, in which a greater increase in the $\mathrm{IC}_{50-\mathrm{DEX}}$ with SER was present in the PTSD than comparison group even though the $\mathrm{IC}_{50-\mathrm{DEx}}$ started out lower in subjects with PTSD (adjusted mean (SE) of the $\mathrm{IC}_{50-\mathrm{DEX}}$ in the PTSD group for cells incubated with DEXonly was $4.393 \mathrm{nM}(0.458)$, and $8.322 \mathrm{nM}$ (1.055) for cells incubated with DEX + SER). In contrast, the adjusted means 
Table I Clinical Characteristics of Subjects with and without Lifetime PTSD

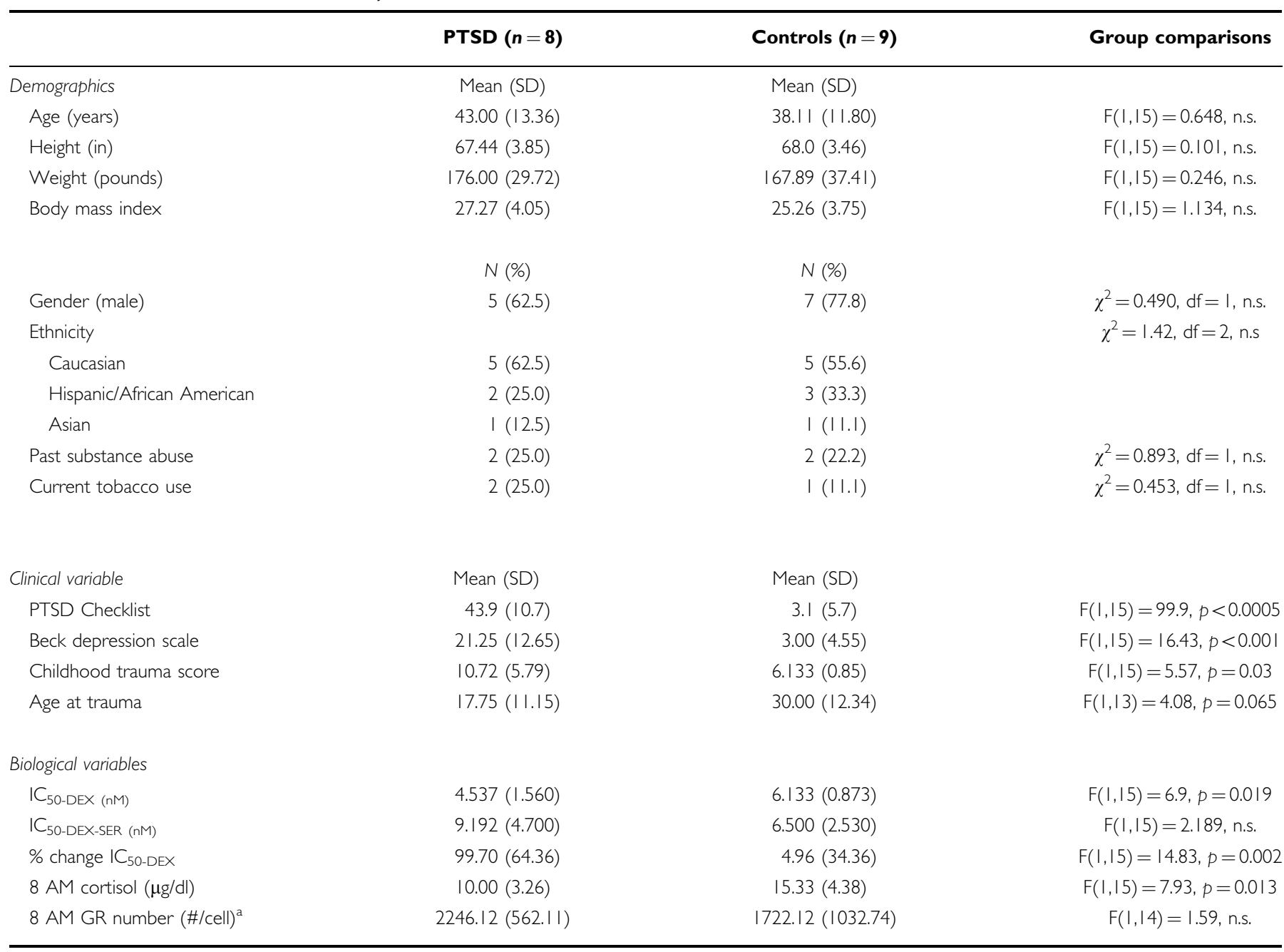

n.s. $=$ not significant.

${ }^{a} \mathrm{GR}$ data missing from one subject due to insufficient blood volume for analysis.

for the comparison group demonstrates almost no change in the $\mathrm{IC}_{50}$ from the DEX-only to the DEX + SER condition (adjusted means (SE): $6.262 \mathrm{nM}(0.430)$ vs $7.247 \mathrm{nM}(0.991)$, respectively). When data were analyzed by paired sample $t$-tests, there was a significant difference in the $\mathrm{IC}_{50 \text {-DEX }}$ with and without SER in the PTSD + group $(t=-3.48$, $\mathrm{df}=7, p=0.010)$ but not the control group $(t=-0.59$, $\mathrm{df}=8, p=0.63$ ).

With respect to correlations among the biological variables, baseline cortisol levels were significantly associated with $\mathrm{IC}_{50-\mathrm{DEX}}(r=0.599, n=17, p=0.011)$, suggesting that higher ambient cortisol was associated with a relatively diminished glucocorticoid responsiveness, but not with other biological variables. GR number was not significantly correlated with any of the measures reflecting the relative activity of lysozyme. Significant correlations were present between severity of childhood trauma and $\mathrm{IC}_{50 \text {-DEX-SER }}(r=0.555, n=17, p=0.021)$ as well as the percent change in $\mathrm{IC}_{50-\mathrm{DEX}}(r=0.593, n=17, p=0.012)$.

Figure 3 demonstrates the relationships between percent change in $\mathrm{IC}_{50-\mathrm{DEX}}$ and PTSD symptoms to illustrate that relationships between this biologic measure and symptoms severity are driven by the PTSD group. Similar, but more modest correlations with PTSD and with depression symptoms were observed for the $\mathrm{IC}_{50-\mathrm{DEX}}(r=-0.435$, $p=0.081$ and $r=-0.469, p=0.057$, respectively) and the $\mathrm{IC}_{50-\mathrm{DEX}-\mathrm{SER}}(r=0.505, p=0.039$ and $r=-0.469, p=0.496)$.

\section{DISCUSSION}

As hypothesized, the effect of SER in PTSD was to increase the $\mathrm{IC}_{50-\mathrm{DEX}}$ for the inhibition of lysozyme, consistent with decreasing the responsiveness of the cell to glucocorticoids. No effect of SER was observed on the lysozyme IC $_{50 \text {-DEx }}$ of comparison subjects. This finding demonstrates that SER may have direct effects on a functional measure of glucocorticoid sensitivity, alterations of which have been proposed as potentially central to the pathophysiology of PTSD, while having far less an effect on this measure in the cells cultured from persons without current or lifetime psychiatric disorder. 

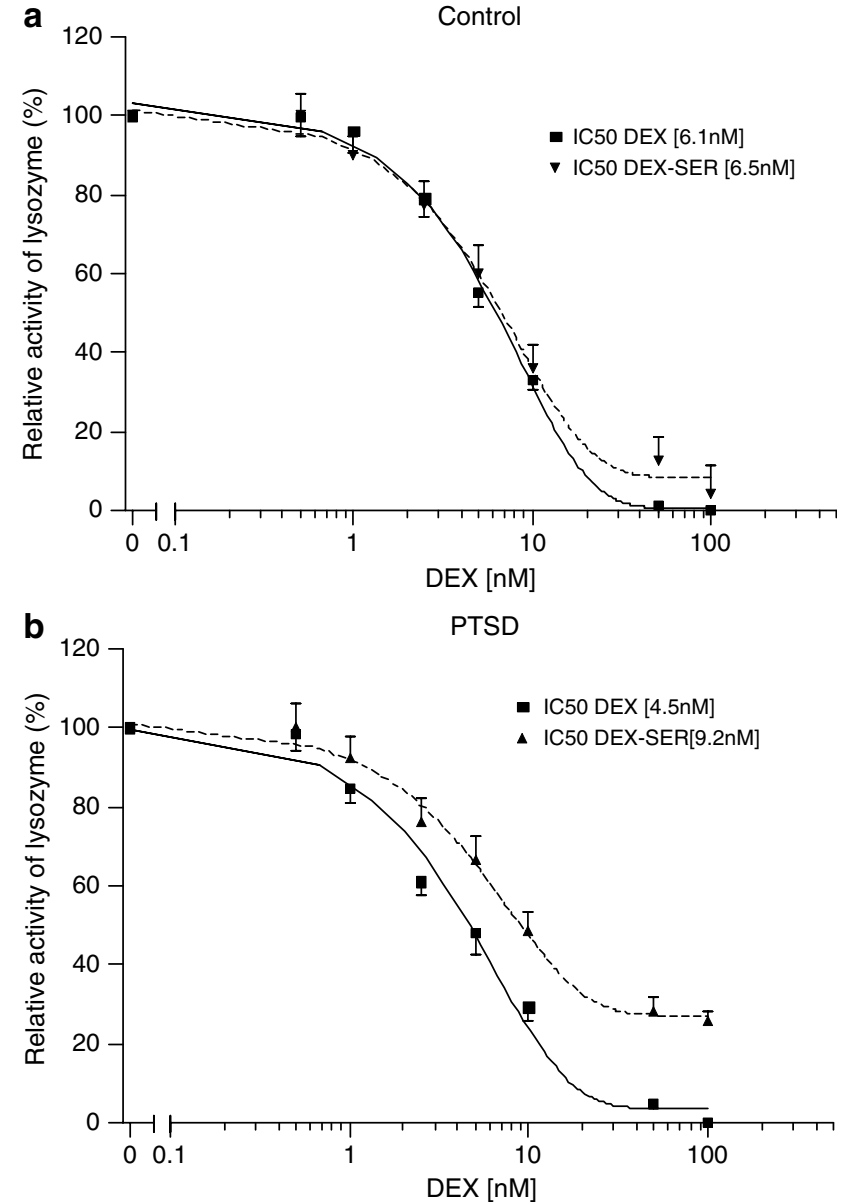

Figure I Inhibition of lysozyme activity by DEX and the effect of SER in human peripheral lymphocytes. Represents mean with SE of inhibition curves from nine control (a) and eight PTSD (b) subjects.

This study did not set out to examine the mechanisms of action of SER, as these have been well studied using a variety of more appropriate methodologies. Rather, the purpose was to examine whether SER has a differential effect on a measure of functional GR responsiveness in PTSD. The use of an in vitro model allowed examination of these effects without consideration of pharmacodynamic and other potential confounds that would be associated with either acute or long-term in vivo treatment studies. Indeed, this is the first study that has examined the effects of SER on GR function in vitro.

Given the well-established effects of antidepressants in enhancing glucocorticoid responsiveness in in vitro studies of neuronal cell cultures (Pepin et al, 1989; Okugawa et al, 1999; Hery et al, 2000; Lai et al, 2003), fibroblasts (Pepin et al, 1992; Pariante et al, 2003a, b; Miller, 2002), and MNL (Vedder et al, 1999) it is challenging to consider the mechanism through which SER administration would result in the opposite effect, that of decreasing glucocorticoid responsiveness in PTSD. One mechanism through which SER and other antidepressants are thought to reverse glucocorticoid resistance associated with GR downregulation, and increased feedback sensitivity, is through their ability to inhibit membrane steroid transporters, in

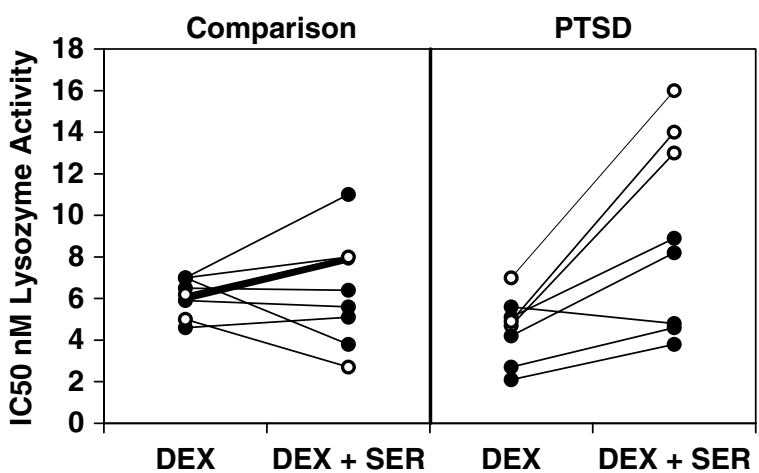

Figure 2 Inhibition of lysozyme activity by DEX and by DEX + SER in peripheral lymphocytes for each of the comparison and PTSD subjects Raw $I_{50}$ data obtained from cells of PTSD and comparison subjects. Closed circles represent data from men and open circles represent data from women. Mean IC 50-DEX $(95 \% \mathrm{Cl})$ for PTSD + $(4.53 \mathrm{nM}(3.60,5.48))$ and controls $(6.13 \mathrm{nM}(5.25,7.02))$. Mean $\mathrm{IC}_{50} \mathrm{DEX}+\mathrm{SER}(95 \% \mathrm{Cl})$ for PTSD + $(9.16 \mathrm{nM}(6.37,11.95))$ and controls $(6.50 \mathrm{nM}(3.87,9.13))$

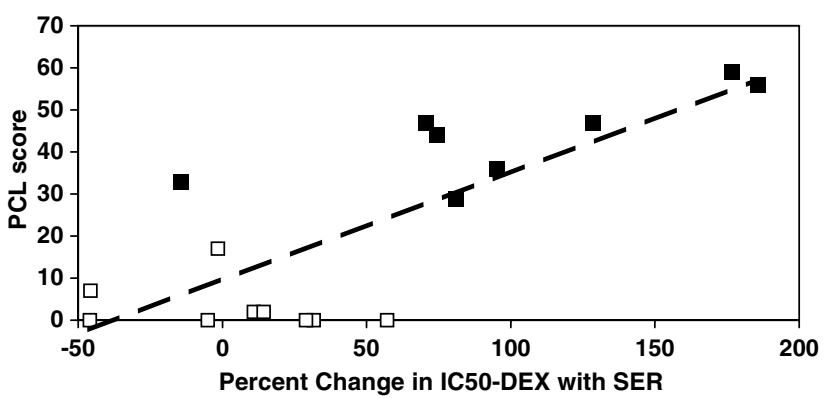

Figure 3 Correlation between PTSD symptom severity and percent change in IC $50-D E X$ with SER. This figure demonstrates the correlations between percent change in the IC 50 -DEX with SER and PTSD symptom severity, as determined by the PTSD Symptom Checklist. The PTSD group $(n=8)$ is represented by filled squares, the comparison subjects $(n=9)$ by open squares. The dotted line shows the trend line for the entire sample, $r=0.791, p<0.0001$.

particular, the steroid transporter $p$-glycoprotein (Weiss et al, 2003; Pariante et al, 2003a, b). Responsiveness to glucocorticoids is thought to be reduced in MDD as a consequence of a cascade in which increased hypothalamic CRF release results in adrenal cortisol hypersecretion (Gold et al, 1986), leading to a downregulation of GR, presumably as a compensatory adaptation that protects the cell from the deleterious consequences of hypercortisolism as are evident in endocrinopathies such as Cushing's disease. The decreased number of GR results in a reduced cortisolnegative feedback, facilitating CRF hypersecretion. By inhibiting the transporter that expels cortisol from cells, antidepressants are thought to make more intracellular cortisol available for binding to GR, which in depression results first in a restoration of GR-mediated gene transcription, and consequently, of negative feedback inhibition, decreased peripheral cortisol levels, and finally, restoration of GR.

Although there is evidence for increased CRF release in PTSD (Bremner et al, 1997; Baker et al, 1997), the cascade of 
ensuing neuroendocrine alterations appears to be different from that associated with MDD (Yehuda, 2002). Rather than resulting in adrenal cortisol hypersecretion, there is evidence for reduced ambient cortisol levels, which may be related to either reduced adrenal output or increased inhibition of ACTH release. The latter explanation is supported by findings demonstrating that the ACTH and cortisol responses to orally ingested DEX are equally suppressed in PTSD (Yehuda et al, 2004).

Regardless of the mechanisms that may account for observations of reduced cortisol levels, particularly in the face of CRF hypersecretion in PTSD, assuming that the actions of SER are to inhibit the steroid-sensitive membrane transporter, it becomes necessary to understand the impact this inhibition would have under conditions in which there is already an increased responsiveness of the cell to glucocorticoids (Yehuda et al, 2004). To the extent that the increased responsiveness to glucocorticoids in PTSD is amplified by reduced cortisol availability to cells, increasing cortisol availability in the cell with antidepressant treatment may result directly in a downregulation of both cytosolic and nuclear GR receptors, leading to a decreased cortisolnegative feedback inhibition. Indeed, although under most circumstances, antidepressant administration results in an activation of GR, under specific conditions (such as coincubation with corticosterone or preincubation with antidepressants), they have also been found to downregulate GR (Pariante et al, 1997, 2001; Budziszewska et al, 2000; Miller, 2002; Yau et al, 2001). In particular, short-term in vitro treatment with antidepressants leads to activation of GR translocation, which in turn leads to acute downregulation of GR expression, which can then be measured as reduced function (Pariante et al, 1997, 2003a, b). Thus, the current study is not completely inconsistent with the available literature.

The interpretations of the current findings rest on the assumption that SER, like other antidepressants, exerts its effects principally by increasing the availability of cortisol within cells. To the extent that this is true, we reasoned that the difference in the lysozyme IC $_{50-D E X}$ under conditions of incubation with and without SER in this experimental model would be analogous to the effects observed in PTSD following DEX ingestion. The variable 'percent change of the lysozyme $\mathrm{IC}_{50-\mathrm{DEX}}$ ' is conceptually analogous to the variable of 'percent cortisol suppression' that we have previously suggested best characterizes the cortisol response to oral DEX administration (Yehuda, 2002). In PTSD, the percent suppression of cortisol following 0.5 and $0.25 \mathrm{mg}$ DEX has been demonstrated to be increased compared to nonpsychiatric as well as other psychiatric groups (Yehuda et al, 1995, 2004; Stein et al, 1997). That percent change of the lysozyme $\mathrm{IC}_{50-\mathrm{DEX}}$ in blood cells in PTSD demonstrated an analogous effect supports the notion that increasing the availability of glucocorticoids was a consequence of coincubation of DEX and SER. That this measure strongly correlated with PTSD and depressive symptoms suggests that SER alters a biologic process that is relevant to the severity symptoms in PTSD. We cannot rule out the possibility that the effects observed result not from the direct effects of SER on the membrane steroid transporter, but on other cellular events shown to be altered in response to antidepressants in vitro. For example, SSRIs, including SER, have been shown to change the balance of cytokine networks that normally modulate GR affinity (Maes 2001; Maes et al, 1999). Furthermore, antidepressants could directly affect the actions of DEX by inhibiting DEXinduced transcription, even in the face of increasing GR translocation (Okuyama-Tamura et al, 2003; Budziszewska et al, 2000).

Two important limitations of this study are the small sample size, which increases the possibility of observing random effects, and the use of a single low dose of SER. Notwithstanding these limitations and that there might be any number of mechanisms contributing to antidepressant actions related to HPA function, the current finding demonstration of significant group differences in the lysozyme $\mathrm{IC}_{50-\mathrm{DEX}}$ in the absence of coincubation with SER suggests that the action of SER in the MNL of subjects with PTSD may reflect accommodations to increased glucocorticoid responsiveness.

In sum, the current findings have several important implications. First, they provide further support of relatively increased glucocorticoid responsivity in PTSD by constituting an independent replication of the finding that response to DEX is increased in MNL from PTSD subjects compared to controls (ie of a decreased lysozyme $\mathrm{IC}_{50-\mathrm{DEX}}$ ), and of low ambient 0800 cortisol levels in PTSD. Although single determinations have not always shown significant differences in cortisol levels between PTSD and comparison subjects (Yehuda et al, 2002, 2004; Altemus et al, 2003) in this small sample, a significantly lower mean ambient cortisol level was demonstrated for PTSD subjects whose glucocorticoid responsivity was increased, replicating prior work (Yehuda et al, 1995, 2002).

Second, since the effects of SER in the PTSD group were to reduce the cells' sensitivity to glucocorticoids, the findings suggest that the therapeutic effects of SER may involve altering glucocorticoid sensitivity. Such an effect might be relevant to understanding why systemic cortisol administration has recently been shown to be useful in preventing as well as alleviating symptoms of PTSD (Schelling et al, 2001; Aerni et al, 2004). Third, because the effects of SER in MNL from subjects with PTSD are directionally different than what would be expected in MDD, the findings suggest a broader view of the effects of antidepressants on the HPA axis that may account for the efficacy of these medications in a wide range of conditions, only some of which are associated with hypercortisolism and/or reduced negative feedback inhibition. That these effects have not been highlighted in previous work may reflect efforts to examine the effects of antidepressants in experimental paradigms or animal models specifically designed to mimic hypercortisolism. However, different effects might be observed in animal models designed to mimic enhanced negative feedback inhibition or increased GR function - a possibility that can easily be tested by developing animal models of PTSD, such as, for example, the creation of transgenic mice designed to show augmented, rather than reduced, GR expression (eg Barden et al, 1997). Such models would serve to provide confirmatory evidence that the effect of antidepressants may be directionally different under alternate regulatory states of the HPA axis. To the extent that HPA axis changes are related to response to SSRIs, increasing the cells access to 
glucocorticoids may be the common denominator in the pharmacologic treatment of PTSD and major depression, even though this increased access may be beneficial in these two disorders for very different reasons.

\section{ACKNOWLEDGEMENTS}

We thank Betty Liong, Karina Stavitsky, and William Blair for assisting in recruiting and maintaining subject data and the database, Drs Alicia Hirsch and Ellen Labinsky for assistance with diagnostic evaluations, and Drs Ling-Song Guo and Iouri Makotkine for assistance with laboratory assays. This study was supported by an unrestricted educational grant from Pfizer, Inc.

\section{REFERENCES}

Aerni A, Traber R, Hock C, Roozendaal B, Schelling G, Papassotiropoulos A et al (2004). Low-dose cortisol for symptoms of posttraumatic stress disorder. Am J Psychiatr 161: $1488-1490$.

Altemus M, Cloitre M, Dhabhar FS (2003). Enhanced cellular immune response in women with PTSD related to childhood abuse. Am J Psychiatr 160: 1705-1707.

American Psychiatric Association (1994). Diagnostic and Statistical Manual of Mental Disorders DSM-IV, 4th edn (Paperback).

Baker DG, West SA, Orth DN, Hill KK, Nicholson WE, Ekhator NN et al (1997). Cerebrospinal fluid and plasma beta-endorphin in combat veterans with post-traumatic stress disorder. Psychoneuroendocrinology 22: 517-529.

Barden N, Stec IS, Montkowski A, Holsboer F, Reul JM (1997). Endocrine profile and neuroendocrine challenge tests in transgenic mice expressing antisense RNA against the glucocorticoid receptor. Neuroendocrinology 66: 212-220.

Beck AT, Ward CH, Mendelson M, Mock J, Erbaugh J (1961). An inventory for measuring depression. Arch Gen Psychiatr 4: 53-63.

Bernstein DP, Fink L, Handelsman L, Foote J, Lovejoy M, Wenzel K et al (1994). Initial reliability and validity of a new retrospective measure of child abuse and neglect. Am J Psychiatr 151: $1132-1136$.

Blake DD, Weathers FW, Nagy LM, Kaloupek DG, Gusman FD, Charney DS et al (1995). The development of a ClinicianAdministered PTSD Scale. J Trauma Stress 8: 75-90.

Blanchard EB, Jones-Alexander J, Buckley TC, Forneris CA (1996). Psychometric properties of the PTSD Checklist (PCL). Behav Res Ther 34: 669-673.

Brady K, Pearlstein T, Asnis GM, Baker D, Rothbaum B, Sikes CR et al (2000). Efficacy and safety of sertraline treatment of posttraumatic stress disorder: a randomized controlled trial. JAMA 283: 1837-1844.

Bremner JD, Licinio J, Darnell A, Krystal JH, Owens MJ, Southwick SM et al (1997). Elevated CSF corticotropin-releasing factor concentrations in posttraumatic stress disorder. Am J Psychiatr 154: 624-629.

Budziszewska B, Jaworska-Deil L, Kajta M, Lason W (2000). Antidepressant drugs inhibit glucocorticoid receptor-mediated gene transcription - a possible mechanism. Br J Pharmacol 130: 1385-1393.

Castaing M, Brouant P, Loiseau A, Santelli-Rouvier C, Santelli M, Alibert-Franco $S$ et al (2000). Membrane permeation by multidrug-resistance-modulators and non-modulators: effects of hydrophobicity and electric charge. J Pharm Pharmacol 52: 289-296.

Cole TJ, Harris HJ, Hoong I, Solomon N, Smith R, Krozowski Z et al (1999). The glucocorticoid receptor is essential for maintaining basal and dexamethasone-induced repression of the murine corticosteroid-binding globulin gene. Mol Cell Endocrinol 154: 29-36.

Davidson JR, Rothbaum BO, Van Der Kolk BA, Sikes CR, Farfel GM (2001). Multicenter, double-blind comparison of sertraline and placebo in the treatment of posttraumatic stress disorder. Arch Gen Psychiatr 58: 485-492.

Ekins S, Kim RB, Leake BF, Dantzig AH, Schuetz EG, Lan LB et al (2002). Application of three-dimensional quantitative structureactivity relationships of P-glycoprotein inhibitors and substrates. Mol Pharmacol 61: 974-981.

Ford JM (1996). Experimental reversal of $P$-glycoprotein-mediated multidrug resistance by pharmacological chemosensitisers. Eur J Cancer 32A: 991-1001.

Gold PW, Loriaux DL, Roy A, Kling MA, Calabrese JR, Kellner CH et al (1986). Responses to corticotropin-releasing hormone in the hypercortisolism of depression and Cushing's disease. Pathophysiologic and diagnostic implications. $N$ Engl J Med 314: 1329-1335.

Green BL (1996). In: Stamm BH (ed). Measurement of Stress, Trauma, and Adaptation. Sidran: Lutherville, MD. pp 366-369.

Hery M, Semont A, Fache MP, Faudon M, Hery F (2000). The effects of serotonin on glucocorticoid receptor binding in rat raphe nuclei and hippocampal cells in culture. J Neurochem 74: 406-413.

Holsboer F (2000). The corticosteroid receptor hypothesis of depression. Neuropsychopharmacology 23: 477-501.

Lai M, Mccormick JA, Chapman KE, Kelly PA, Seckl JR, Yau JL (2003). Differential regulation of corticosteroid receptors by monoamine neurotransmitters and antidepressant drugs in primary hippocampal culture. Neuroscience 118: 975-984.

Maes M (2001). The immunoregulatory effects of antidepressants. Hum Psychopharmacol 16: 95-103.

Maes M, Song C, Lin AH, Bonacorso S, Kenis G, De Jongh R et al (1999). Negative immunoregulatory effects of antidepressants: inhibition of interferon-gamma and stimulation of interleukin10 secretion. Neuropsychopharmacology 20: 370-379.

McQuade R, Young AH (2000). Future therapeutic targets in mood disorders: the glucocorticoid receptor. J Psychiatry 177: 390-395.

Miller AH, Vogt GJ, Pearce BD (2002). The phosphodiesterase type 4 inhibitor, rolipram, enhances glucocorticoid receptor function. Neuropsychopharmacology 27: 939-948.

Nemeroff CB (1996). The corticotropin-releasing factor (CRF) hypothesis of depression: new findings and new directions. $\mathrm{Mol}$ Psychiatr 1: 336-342.

Nemeroff CB, Owens MJ (2004). Pharmacologic differences among the SSRIs: focus on monoamine transporters and the HPA axis. CNS Spectr 9(6 Suppl 4): 23-31.

Nestler EJ (1998). Antidepressant treatments in the 21st century. Biol Psychiatr 44: 526-533.

Okugawa G, Omori K, Suzukawa J, Fujiseki Y, Kinoshita T, Inagaki C (1999). Long-term treatment with antidepressants increases glucocorticoid receptor binding and gene expression in cultured rat hippocampal neurones. J Neuroendocrinol 11: 887-895.

Okuyama-Tamura M, Mikuni M, Kojima I (2003). Modulation of the human glucocorticoid receptor function by antidepressive compounds. Neurosci Lett 342: 206-210.

Panarelli M, Holloway CD, Mulatero P, Fraser R (1994). Inhibition of lysozyme synthesis by dexamethasone in human mononuclear leukocytes: an index of glucocorticoid sensitivity. J Clin Endocrinol Metab 78: 872-877.

Pariante CM, Hye A, Williamson R, Makoff A, Lovestone S, Kerwin RW (2003). The antidepressant clomipramine regulates cortisol intracellular concentrations and glucocorticoid receptor expression in fibroblasts and rat primary neurones. Neuropsychopharmacology 28: 1553-1561. 
Pariante CM, Miller AH (2001). Glucocorticoid receptors in major depression: relevance to pathophysiology and treatment. Biol Psychiatr 49: 391-404.

Pariante CM, Pearce BD, Pisell TL, Owens MJ, Miller AH (1997). Steroid-independent translocation of the glucocorticoid receptor by the antidepressant desipramine. Mol Pharmacol 52: 571-581.

Pariante CM, Pearce BD, Pisell TL, Su C, Miller AH (2001). The steroid receptor antagonists RU40555 and RU486 activate glucocorticoid receptor translocation and are not excreted by the steroid hormones transporter in L929 cells. J Endocrinol 169: 309-320.

Pariante CM, Kim RB, Makoff A, Kerwin RW (2003). Antidepressant fluoxetine enhances glucocorticoid receptor function in vitro by modulating membrane steroid transporters. $\mathrm{Br} J$ Pharmacol 139: 1111-1118.

Pepin MC, Beaulieu S, Barden N (1989). Antidepressants regulate glucocorticoid receptor messenger RNA concentrations in primary neuronal cultures. Brain Res Mol Brain Res 6: 77-83.

Pepin MC, Govindan MV, Barden N (1992). Increased glucocorticoid receptor gene promoter activity after antidepressant treatment. Mol Pharmacol 41: 1016-1022.

Schafer WR (1999). How do antidepressants work? Prospects for genetic analysis of drug mechanisms. Cell 98: 551-554.

Schelling G, Briegel J, Roozendaal B, Stoll C, Rothenhausler HB, Kapfhammer HP (2001). The effect of stress doses of hydrocortisone during septic shock on posttraumatic stress disorder in survivors. Biol Psychiatr 50: 978-985.

Spitzer RL, Williams JBW, Gibbon M (1995). Structured Clinical Interview for DSM-IV (SCID) New York. New York State Psychiatric Institute, Biometrics Research: New York.

Stein MB, Yehuda R, Koverola C, Hanna C (1997). Enhanced dexamethasone suppression of plasma cortisol in adult women traumatized by childhood sexual abuse. Biol Psychiatr 42: $680-686$.

Vedder H, Bening-Abu-Shach U, Lanquillon S, Krieg JC (1999). Regulation of glucocorticoid receptor-mRNA in human blood cells by amitriptyline and dexamethasone. J Psychiatr Res 33: 303-308.
Weiss J, Dormann SM, Martin-Facklam M, Kerpen CJ, Ketabi-Kiyanvash N, Haefeli WE (2003). Inhibition of P-glycoprotein by newer antidepressants. J Pharmacol Exp Ther 305: 197-204.

Yau JL, Noble J, Hibberd C, Seckl JR (2001). Short-term administration of fluoxetine and venlafaxine decreases corticosteroid receptor mRNA expression in the rat hippocampus. Neurosci Lett 306: 161-164.

Yehuda R (2002). Current status of cortisol findings in posttraumatic stress disorder. Psychiatr Clin North Am 25: 341-368.

Yehuda R, Boisoneau D, Lowy MT, Giller Jr EL (1995). Doseresponse changes in plasma cortisol and lymphocyte glucocorticoid receptors following dexamethasone administration in combat veterans with and without posttraumatic stress disorder. Arch Gen Psychiatr 52: 583-593.

Yehuda R, Halligan SL, Grossman R, Golier JA, Wong C (2002). The cortisol and glucocorticoid receptor response to low dose dexamethasone administration in aging combat veterans and holocaust survivors with and without posttraumatic stress disorder. Biol Psychiatr 52: 393-403.

Yehuda R, Teicher MH, Trestman RL, Levengood RA, Siever LJ (1996). Cortisol regulation in posttraumatic stress disorder and major depression: a chronobiological analysis. Biol Psychiatr 40: 79-88.

Yehuda R, Yang RK, Guo SL, Makotkine I, Singh B (2003). Relationship between dexamethasone-inhibited lysozyme activity in peripheral mononuclear leukocytes and the cortisol and glucocorticoid receptor response to dexamethasone. J Psychiatr Res 37: 471-477.

Yehuda R, Marshall R, Penkower A, Wong C (2002). Pharmacological treatment for post traumatic stress disorder. In: Natham P, Gorman JM (eds). A Guide to Treatments That Work, 2nd edn. Oxford University: London, England. pp 411-445.

Yehuda R, Yang RK, Golier JA, Tischler L, Liong B, Decker K (2004). Effect of topiramate on glucocorticoid receptors in mononuclear leukocytes. Neuropsychopharmacology 29: 433-439. 